\title{
High-Flow Nasal Oxygen Therapy Outside the Intensive Care Setting: How Safe Is Safe Enough?
}

Oxygen interface choices have recently been broadened with the arrival of high-flow nasal canula (HFNC) oxygen therapy. HFNC avoids several drawbacks of low-flow interfaces: ${ }^{1-3}$ the $\mathrm{F}_{\mathrm{IO}_{2}}$ can be precisely adjusted, with a flow that better matches patient's inspiratory flow demand; the humidified and heated gas provides better comfort compared with other interfaces; $;, 5$ and the high flow induces a certain level of positive expiratory pressure, ${ }^{6,7}$ which, therefore, contributes to lung aeration enhancement ${ }^{8,9}$ and anatomic dead space clearance. ${ }^{10}$

Its use in the ICU comprises use for evaluations at ICU admission (or respiratory failure onset), during the preoxygentation period, ${ }^{11-14}$ and after extubation. ${ }^{15-17}$ HFNC for treatment of hypoxemic respiratory failure has been investigated in different populations. The FLORALI randomized controlled trial ${ }^{18}$ became a landmark in HFNC evaluation. It provided evidence of a significant reduction in ICU and 90-d mortality in subjects treated with HFNC compared with subjects who received conventional oxygen therapy or a combination strategy of noninvasive ventilation and HFNC. Such enthusiastic results were not confirmed in patients who were immunocompromised. ${ }^{19,20} \mathrm{~A}$ recent meta-analysis including subjects in the emergency department found no effect of HFNC over conventional oxygen therapy on mortality, but a significant reduction of the need for invasive mechanical ventilation or escalation of oxygen therapy. ${ }^{21}$ In the ICU, a next step would be the investigation of hypercapnic respiratory failure. ${ }^{22}$

This promising technique has scarcely been investigated outside the ICU. Nevertheless, applying HFNC outside the ICU is an important challenge. The shortage of ICU beds and the high cost of ICU stays might contribute to the spread of this technique outside the ICU. The main challenge, therefore, would be the identification of patients who could benefit the most from HFNC, outside the ICU, with less risk of an unfavorable outcome.

\footnotetext{
Dr Messika discloses relationships with Fisher \& Paykel and CSL Behring. Dr Ricard discloses a relationship with Fisher \& Paykel.
}

Correspondence: Jonathan Messika MD PhD, Pulmonology and Lung Transplant Unit, AP-HP, Hôpital Bichat-Claude Bernard, 46 rue Henri Huchard, F-75018 Paris, France. E-mail: jonathan.messika@aphp.fr.

DOI: $10.4187 /$ respcare.07441
Although some studies focused on its emergency department use, ${ }^{23-28}$ which showed that HFNC is safe and effective in the emergency department compared with noninvasive ventilation and conventional oxygen therapy, a limited number of those studies reported HFNC use outside the ICU. Kang et $\mathrm{al}^{29}$ focused on subjects for whom the therapy failed and who were eventually transferred to

See the Original Study on Page 1333

the ICU. In this study, a fourth of subjects for whom the therapy failed were intubated after $48 \mathrm{~h}$ of HFNC therapy, with a median HFNC duration of $126 \mathrm{~h}$. This group had a significantly higher ICU mortality than subjects intubated in the first $48 \mathrm{~h}$ after HFNC therapy $(39.2 \%$ vs $66.7 \%$, $P=.001)$. This study raised important concerns regarding the safety of HFNC outside the ICU, and its potential risks in delaying intubation when patients with severe conditions are hospitalized in a ward where monitoring is less frequent than in the ICU or the emergency department..$^{30}$ In the study by Pirret et al, ${ }^{31}$ the 67 subjects who received HFNC in the wards significantly improved physiologic variables (ie, breathing frequency, $\mathrm{S}_{\mathrm{pO}_{2}}$, and heart rate) after the initiation of HFNC, and a very limited proportion of subjects suffered deterioration and were transferred to the ICU or a high-dependence unit $(4.5 \%$ and $4.5 \%$, respectively).

Zemach et $\mathrm{al}^{32}$ add very interesting data on HFNC use outside the ICU. In their real-life prospective observational study, they included consecutive adult subjects who required HFNC for respiratory failure in medical wards, the intermediate care unit, and the emergency department of their institution. In total, 111 subjects were included, and a composite outcome was defined as the absence of intubation, ICU admission, and death during a hospital stay. ${ }^{32}$ The investigators report a significant alleviation of respiratory distress and dyspnea after HFNC in the wide majority of subjects $(81 \%, 95 \%$ CI $72.5 \%-87.9 \%) .^{32}$ Interestingly, the alleviation of dyspnea was significantly lower in subjects who were unable to reach the composite outcome. Overall mortality reached $50 \%$, but, when the investigators limited their analysis to subjects without donot-escalate therapies orders, overall mortality was $26 \% .^{32}$ 


\section{EDITORIALS}

Although limited, the mortality rate of this cohort ${ }^{32}$ remains high. One might wonder if the high mortality is primarily the effect of applying HFNC in a setting of less frequent monitoring than in the ICU to subjects with acute respiratory failure and if a closer monitoring would have allowed a better prognosis. To date, physicians' tools to predict HFNC failure have only been assessed in the ICU. ${ }^{33-36}$ The resolution of clinical respiratory failure features (breathing frequency, thoraco-abdominal asynchrony $)^{35}$ and the persistence of respiratory discomfort after the first hour ${ }^{33}$ have been associated with a worst outcome. Roca et al described ${ }^{34}$ and validated ${ }^{36}$ the ROX index, a physiologic index defined as the ratio of oxygenation (assessed by $\mathrm{S}_{\mathrm{pO}_{2}} / \mathrm{F}_{\mathrm{IO}_{2}}$ ) to the breathing frequency. A ROX index that exceeds 4.88 at $12 \mathrm{~h}$ of HFNC less likely to fail than the noninvasive strategy. ${ }^{34}$ In the present study by Zemach et al, ${ }^{32}$ the ROX index was calculated much sooner (30 min after HFNC initiation) and was the only independent predictor of successful therapy in multivariate analysis, which indicates that the ROX index might be a valuable tool to predict HFNC failure in patients who are receiving HFNC, even outside the ICU.

An additional point is of paramount importance: the use of HFNC in patients with do-not-resuscitate orders. Obviously, these subjects would not have benefited from ICU admission in terms of escalation of life support. However, the alleviation of dyspnea, similar to patients without a do-not-resuscitate order as well as the decrease in breathing frequency are major reasons to provide HFNC treatment to patients who, in a vast majority $(93 \%$ in this study), will finally die. Furthermore, it has previously been shown that HFNC could actually treat hypoxemic acute respiratory failure in patients with a do-not-resuscitate or$\operatorname{der}^{37}$ and allow a favorable outcome.

Although convincing, the data provided by Zemach et al ${ }^{32}$ should be taken with caution. First, although the study was prospective, no predefined criteria for intensivist consultation or ICU admission were determined; and the high mortality rates in the subjects without a do-not-resuscitate order renders questionable their initial assessment. One can assume that some subjects' severity might have been underevaluated. Next, the flows applied were relatively low, with mean flows between 45 and $50 \mathrm{~L} / \mathrm{min}$, which is clearly underdosing the therapy.

HFNC is definitely a therapy that can be used outside the ICU. In their article, Zemach et $\mathrm{al}^{32}$ provide data that support the diffusion of this technique into the wards. Nevertheless, caution should be the rule, and close monitoring, if not continuous, should be applied by skilled teams. Simple clinical parameters, or their combination using the the ROX index, ought to be scrutinized to avoid a delayed intubation. A misuse would result in jeopardizing this useful and effective technique.

Jonathan Messika

Pulmonology and Lung Transplant Unit APHP.Nord Université de Paris Hôpital Bichat-Claude Bernard Paris, France Physiopathology and Epidemiology of Respiratory Diseases Université de Paris PHERE

UMR1152

Institut National de la Santé et de la

Recherche Médicale

Paris Transplant Group Paris, France

Jean-Damien Ricard Medico-Surgical Intensive Care Unit APHP.Nord Université de Paris Hôpital Louis Mourier Colombes, France Infection, Antimicrobials, Modelling, Evolution Université de Paris

IAME

UMR 1137

Institut National de la Santé et de la Recherche Médicale Paris, France

\section{REFERENCES}

1. Ricard JD. High flow nasal oxygen in acute respiratory failure. Minerva Anestesiol 2012;78(7):836-841.

2. Spoletini G, Alotaibi M, Blasi F, Hill NS. Heated humidified highflow nasal oxygen in adults: mechanisms of action and clinical implications. Chest 2015;148(1):253-261.

3. Papazian L, Corley A, Hess D, Fraser JF, Frat JP, Guitton C, et al. Use of high-flow nasal cannula oxygenation in ICU adults: a narrative review. Intensive Care Med 2016;42(9):1336-1349.

4. Cuquemelle E, Pham T, Papon JF, Louis B, Danin PE, Brochard L. Heated and humidified high-flow oxygen therapy reduces discomfort during hypoxemic respiratory failure. Respir Care 2012;57(10):15711577.

5. Frat JP, Brugiere B, Ragot S, Chatellier D, Veinstein A, Goudet V, et al. Sequential application of oxygen therapy via high-flow nasal cannula and noninvasive ventilation in acute respiratory failure: an observational pilot study. Respir Care 2015;60(2):170-178.

6. Groves N, Tobin A. High flow nasal oxygen generates positive airway pressure in adult volunteers. Aust Crit Care 2007;20(4):126131.

7. Parke R, McGuinness S, Eccleston M. Nasal high-flow therapy delivers low level positive airway pressure. Br J Anaesth 2009;103(6): 886-890.

8. Riera J, Pérez P, Cortés J, Roca O, Masclans JR, Rello J. Effect of high-flow nasal cannula and body position on end-expiratory lung 


\section{EDITORIALS}

volume: a cohort study using electrical impedance tomography. Respir Care 2013;58(4):589-596.

9. Plotnikow GA, Thille AW, Vasquez DN, Pratto RA, Quiroga CM, Andrich ME, et al. Effects of high-flow nasal cannula on end-expiratory lung impedance in semi-seated healthy subjects. Respir Care 2018;63(8):1016-1023.

10. Möller W, Celik G, Feng S, Bartenstein P, Meyer G, Oliver E, et al. Nasal high flow clears anatomical dead space in upper airway models. J Appl Physiol 2015;118(12):1525-1532.

11. Miguel-Montanes R, Hajage D, Messika J, Bertrand F, Gaudry S, Rafat $\mathrm{C}$, et al. Use of high-flow nasal cannula oxygen therapy to prevent desaturation during tracheal intubation of intensive care patients with mild-to-moderate hypoxemia. Crit Care Med 2015;43(3): 574-583.

12. Jaber S, Monnin M, Girard M, Conseil M, Cisse M, Carr J, et al. Apnoeic oxygenation via high-flow nasal cannula oxygen combined with non-invasive ventilation preoxygenation for intubation in hypoxaemic patients in the intensive care unit: the single-centre, blinded, randomised controlled OPTINIV trial. Intensive Care Med 2016; 42(12):1877-1887.

13. Frat JP, Ricard JD, Coudroy R, Robert R, Ragot S, Thille AW; on behalf of REVA network. Pre-oxygenation with non-invasive ventilation versus high-flow nasal cannula oxygen therapy for intubation of patients with acute hypoxemic respiratory failure in ICU: the prospective randomized controlled FLORALI-2 study protocol. BMJ Open 2017;7(12):e018611

14. Vourc'h M, Asfar P, Volteau C, Bachoumas K, Clavieras N, Egreteau PY, et al. High-flow nasal cannula oxygen during endotracheal intubation in hypoxemic patients: a randomized controlled clinical trial. Intensive Care Med 2015;41(9):1538-1548.

15. Maggiore SM, Idone FA, Vaschetto R, Festa R, Cataldo A, Antonicelli F, et al. Nasal high-flow versus Venturi mask oxygen therapy after extubation. Effects on oxygenation, comfort, and clinical outcome. Am J Respir Crit Care Med 2014;190(3):282-288.

16. Hernández G, Vaquero C, Colinas L, Cuena R, González P, Canabal A, et al. Effect of postextubation high-flow nasal cannula vs noninvasive ventilation on reintubation and postextubation respiratory failure in high-risk patients: a randomized clinical trial. JAMA 2016; 316(15):1565-1574

17. Hernández G, Vaquero C, González P, Subira C, Frutos-Vivar F, Rialp G, et al. Effect of postextubation high-flow nasal cannula vs conventional oxygen therapy on reintubation in low-risk patients: a randomized clinical trial. JAMA 2016;315(13):1354-1361.

18. Frat JP, Thille AW, Mercat A, Girault C, Ragot S, Perbet S, et al.; FLORALI Study Group, REVA Network. High-flow oxygen through nasal cannula in acute hypoxemic respiratory failure. N Engl J Med 2015;372(23):2185-2196.

19. Azoulay E, Lemiale V, Mokart D, Nseir S, Argaud L, Pène F, et al. Effect of high-flow nasal oxygen vs standard oxygen on 28-day mortality in immunocompromised patients with acute respiratory failure: the HIGH randomized clinical trial. JAMA 2018;320(20): 2099-2107.

20. Lemiale V, Resche-Rigon M, Mokart D, Pène F, Argaud L, Mayaux $\mathrm{J}$, et al. High-flow nasal cannula oxygenation in immunocompromised patients with acute hypoxemic respiratory failure: a Groupe de Recherche Respiratoire en Réanimation Onco-Hématologique Study. Crit Care Med 2017;45(3):e274-e280.

21. Rochwerg B, Granton D, Wang DX, Helviz Y, Einav S, Frat JP, et al. High flow nasal cannula compared with conventional oxygen therapy for acute hypoxemic respiratory failure: a systematic review and meta-analysis. Intensive Care Med 2019;45(5):563-572.
22. Ricard JD, Dib F, Esposito-Farese M, Messika J, Girault C; REVA network. Comparison of high flow nasal cannula oxygen and conventional oxygen therapy on ventilatory support duration during acuteon-chronic respiratory failure: study protocol of a multicentre, randomised, controlled trial. The "HIGH-FLOW ACRF" study. BMJ Open 2018;8(9):e022983.

23. Lenglet H, Sztrymf B, Leroy C, Brun P, Dreyfuss D, Ricard JD. Humidified high flow nasal oxygen during respiratory failure in the emergency department: feasibility and efficacy. Respir Care 2012; 57(11):1873-1878

24. Bell N, Hutchinson CL, Green TC, Rogan E, Bein KJ, Dinh MM. Randomised control trial of humidified high flow nasal cannulae versus standard oxygen in the emergency department. Emerg Med Australas 2015;27(6):537-541.

25. Makdee O, Monsomboon A, Surabenjawong U, Praphruetkit N, Chaisirin W, Chakorn T, et al. High-flow nasal cannula versus conventional oxygen therapy in emergency department patients with cardiogenic pulmonary edema: a randomized controlled trial. Ann Emerg Med 2017;70(4):465-472.e2.

26. Rittayamai N, Tscheikuna J, Praphruetkit N, Kijpinyochai S. Use of high-flow nasal cannula for acute dyspnea and hypoxemia in the emergency department. Respir Care 2015;60(10):1377-1382.

27. Jones PG, Kamona S, Doran O, Sawtell F, Wilsher M. Randomized controlled trial of humidified high-flow nasal oxygen for acute respiratory distress in the emergency department: the HOT-ER Study. Respir Care 2016;61(3):291-299.

28. Doshi P, Whittle JS, Bublewicz M, Kearney J, Ashe T, Graham R, et al. High-velocity nasal insufflation in the treatment of respiratory failure: a randomized clinical trial. Ann Emerg Med 2018;72(1):7383.e5.

29. Kang BJ, Koh Y, Lim CM, Huh JW, Baek S, Han M, et al. Failure of high-flow nasal cannula therapy may delay intubation and increase mortality. Intensive Care Med 2015;41(4):623-632.

30. Ricard JD, Messika J, Sztrymf B, Gaudry S. Impact on outcome of delayed intubation with high-flow nasal cannula oxygen: is the device solely responsible? Intensive Care Med 2015;41(6):1157-1158.

31. Pirret AM, Takerei SF, Matheson CL, Kelly M, Strickland W, Harford $\mathrm{J}$, et al. Nasal high flow oxygen therapy in the ward setting: a prospective observational study. Intensive Crit Care Nurs 2017; 42(Can't get issue from record):127-134.

32. Zemach S, Helviz Y, Shitrit M, Friedman R, Levin PD. The use of high-flow nasal cannula oxygen outside the intensive care unit. Respir Care 2019;64(11):1333-1342.

33. Frat JP, Ragot S, Coudroy R, Constantin JM, Girault C, Prat G, et al.; REVA network. Predictors of intubation in patients with acute hypoxemic respiratory failure treated with a noninvasive oxygenation strategy. Crit Care Med 2018;46(2):208-215.

34. Roca O, Messika J, Caralt B, García-de-Acilu M, Sztrymf B, Ricard JD, Mascians JR. Predicting success of high-flow nasal cannula in pneumonia patients with hypoxemic respiratory failure: the utility of the ROX index. J Crit Care 2016;36:200-206.

35. Sztrymf B, Messika J, Bertrand F, Hurel D, Leon R, Dreyfuss D, Ricard JD. Beneficial effects of humidified high flow nasal oxygen in critical care patients: a prospective pilot study. Intensive Care Med 2011;37(11):1780-1786.

36. Roca O, Caralt B, Messika J, Samper M, Sztrymf B, Hernández G, et al. An index combining respiratory rate and oxygenation to predict outcome of nasal high-flow therapy. Am J Respir Crit Care Med 2019;199(11):1368-1376.

37. Peters SG, Holets SR, Gay PC. High-flow nasal cannula therapy in do-not-intubate patients with hypoxemic respiratory distress. Respir Care 2013;58(4):597-600. 